\title{
Twenty-four Months Feeding on Unsaturated Dietary Fats (Virgin Olive, Sunflower, or Fish Oil) Differentially Modulate Gingival Mitochondria in the Rat
}

\author{
María D. Navarro-Hortal ${ }^{1}$, Alfonso Varela-López¹, José M. Romero-Márquez¹, Celia Piquer-Martinez", \\ Pedro Bullón ${ }^{2}$, Tamara Y. Forbes-Hernández ${ }^{3}$, José L. Quiles ${ }^{1, *}$ \\ ${ }^{1}$ Department of Physiology, Biomedical Research Center, Institute of Nutrition and Food Technology "José Mataix Verdú", University of Granada, \\ Avda del Conocimiento sn., Armilla, Granada 18100, Spain \\ ${ }^{2}$ Department of Oral Medicine and Periodontology, University of Seville, Sevilla, Spain \\ ${ }^{3}$ Nutrition and Food Science Group, Department of Analytical and Food Chemistry, CITACA, CACTI, University of Vigo, Vigo, Spain
}

\author{
ARTICLE INFO \\ Article History \\ Received 18 July 2019 \\ Accepted 29 July 2019 \\ Keywords \\ Aging \\ fatty acids \\ gene expression \\ biogenesis \\ autophagy \\ apoptosis
}

\begin{abstract}
This study investigated the effects of feeding rats for 24 months on different unsaturated fats (virgin olive, sunflower, or fish oil) on gingival mitochondrial ultrastructure and expression of genes related to mitochondrial biology as well as the amount of circulating fatty acids in the plasma. Results show that sunflower oil led to a higher mitochondrial area, perimeter, and area:perimeter ratio, markers of swelling, and increased age. Sunflower oil also led to increased gene expression associated to biogenesis, autophagy, oxidative stress, and apoptosis. Genes related to mitochondrial electron chain did not result affected by treatments. As old rats lifelong fed on sunflower oil have previously showed higher alveolar bone resorption, a major feature of periodontitis, we could conclude that age-related alveolar bone resorption associated with n6PUFA would be, at least in part, mediated by changes in mitochondrial ultrastructure and gene expression at the gingival tissue.
\end{abstract}

(c) 2019 International Association of Dietetic Nutrition and Safety. Publishing services by Atlantis Press International B.V. This is an open access article distributed under the CC BY-NC 4.0 license (http://creativecommons.org/licenses/by-nc/4.0/).

\section{INTRODUCTION}

Oral health is of great importance by itself, but also because it has been related with an increasing number of systemic conditions such as cardiovascular or liver diseases [1]. Aging, which is a physiological situation and not a disease, is, however, associated with the so-called age-related diseases. These diseases increase their incidence during aging and interfere with the physiological process of "healthy aging" [2]. Among oral diseases associated with general health, periodontitis characterized by the breakdown of the tooth-supporting tissues and alveolar bone loss has focused attention [3]. A common link among periodontitis, cardiovascular, and liver diseases as well as aging is the importance of dietary habits [4-7]. One of the nutritional factors that affect health to a greater extent is dietary fat, both when considered from the point of view of the total amount of eaten fat as well as when dietary fat type is taken into account [8]. As is well known, the intake of excess of fat, irrespective of its nature, lead to a higher susceptibility to cardiovascular diseases such as atherosclerosis [9] or to the suffering of fatty liver and other nonalcoholic fatty liver disease such as nonalcoholic steatohepatitis (NASH) [10]. In recent years, it has been described how normolipidic diets rich in specific unsaturated fatty acids such as those from seed oils (e.g., sunflower oil) increases

"Corresponding author. Email: jlquiles@ugr.es

Peer review under responsibility of the International Association of Dietetic Nutrition and Safety atherosclerosis, NASH, and periodontitis, all of them particularly during aging [11-13]. The way different unsaturated fats affect health is related to several aspects including their susceptibility to provoke inflammation [14], oxidative stress [15], and of course the consequences derived from the formation of biological membranes enriched in one or another type of fatty acid [16]. The latter has been widely observed in humans and experimental animals that biological membranes and blood adapt to the type of fat in the diet [17]. In this sense, and as with the rest of biological membranes, mitochondria also build their lipid bilayers using part of the fatty acids supplied by the diet [16]. Thus, these organelles, which are involved in aging and the aforementioned diseases, are especially affected by dietary fat and are another route through which fat conditions health [18]. In this way, it has been shown that rats fed throughout their lives with fatty sources enriched in monounsaturated fatty acids such as those from virgin olive oil presented minor alterations associated with age from the point of view of the periodontium [11]. However, when the animals were fed with sunflower oil, a greater resorption of the alveolar bone associated with age was observed [11]. By analyzing the possible mechanisms through which this took place, the mitochondria appeared to play a major role in the process [11].

Based on all the above, the present research has focused on studying the involvement of the mitochondrial ultrastructure of the gingiva of old rats fed with different types of unsaturated fat (virgin olive, sunflower, or fish oil). In addition, the relationship of the 
ultrastructural findings with the gingival expression of a series of genes related to mitochondrial biology as well as the amount of circulating fatty acids in the plasma of rats has been studied.

\section{MATERIALS AND METHODS}

\subsection{Experimental Design}

In this study, 18 male Wistar rats (Rattus norvegicus) initially weighing $80-90 \mathrm{~g}$ were used. They were placed in a thermostated room $\left(20^{\circ} \mathrm{C}\right)$ with cycles of $12 \mathrm{~h}$ of darkness and $12 \mathrm{~h}$ of light for 24 months. Animals were randomized into three experimental groups of 12 animals each that differed in the provided diet. They were fed from weaning until 24 months of age with a semisynthetic and isoenergetic diet according to the AIN93 criteria described by Reeves et al. [19], with the exception of dietary fat, which was, according to the experimental group, virgin olive, sunflower, or fish oil. Up to 2 months of age, the AIN-93G version was administered and from that age until the end of the study, the AIN-93M diet was administered. Table 1 shows the lipid profile of the different experimental diets. Twenty-four months from the beginning of the experiment, six rats were killed per group. The rats were sacrificed by cervical dislocation followed by decapitation, at the same time of day to avoid any circadian fluctuation. The animals were treated in accordance with the guidelines of the Spanish Society of Laboratory Animals and the study was approved by the Ethics Committee of the University of Granada (permit number 20-CEA-2004).

\subsection{Fatty Acid Analysis of Dietary Fats and Plasma}

The fatty acid profile of dietary fats and plasma was determined using the method of Lepage and Roy [20]. A gas-liquid chromatograph Model HP-5890 Series II (Hewlett Packard, Palo Alto, CA, USA) equipped with a flame-ionization detector was used to

Table 1 Fatty acids profile of experimental dietary fats (g/100 g)

\begin{tabular}{|c|c|c|c|}
\hline \multirow{2}{*}{ Fatty acid or index } & \multicolumn{3}{|c|}{ Oils } \\
\hline & Virgin olive & Sunflower & Fish \\
\hline C14:0 & 0.0 & 0.1 & 7.2 \\
\hline C16:0 & 8.3 & 6.4 & 17.1 \\
\hline $\mathrm{C} 16: 1 n-9$ & 1.1 & 0.1 & 9.6 \\
\hline C18:0 & 3.2 & 4.7 & 2.7 \\
\hline $\mathrm{C} 18: 1 n-9$ & 77.7 & 24.2 & 15.1 \\
\hline $\mathrm{C} 18: 2 n-6$ & 3.2 & 62.8 & 2.8 \\
\hline $\mathrm{C} 20: 3 n-6$ & 0.1 & 0.9 & 0.1 \\
\hline $\mathrm{C} 20: 4 n-6$ & 0.0 & 0.0 & 2.1 \\
\hline $\mathrm{C} 20: 5 n-3$ & 0.2 & 0.1 & 18.6 \\
\hline $\mathrm{C} 24: 0$ & 0.0 & 0.1 & 0.3 \\
\hline $\mathrm{C} 24: 1 n-9$ & 0.0 & 0.0 & 0.9 \\
\hline $\mathrm{C} 22: 6 n-3$ & 0.0 & 0.0 & 10.5 \\
\hline Total saturated fatty acids & 12.6 & 11.5 & 30.5 \\
\hline Total monounsaturated fatty acids & 83.7 & 24.4 & 30.1 \\
\hline Total $n-6$ polyunsaturated fatty acids & 3.3 & 63.7 & 8.2 \\
\hline Total $n-3$ polyunsaturated fatty acids & 0.4 & 0.4 & 31.3 \\
\hline Total polyunsaturated fatty acids & 3.7 & 64.1 & 39.4 \\
\hline
\end{tabular}

analyze fatty acids. Chromatography was performed using a $60-\mathrm{m}$ long capillary column, 32-mm i.d., and 20-mm thick impregnated with SpTM 2330 FS (Supelco Inc. Bellefonte, Palo Alto, CA, USA). The injector and detector were maintained at $250^{\circ} \mathrm{C}$ and $275^{\circ} \mathrm{C}$, respectively, nitrogen was used as a carrier gas, and the split ratio was 29:1. Temperature programming (for a total time of $40 \mathrm{~min}$ ) was as follows: initial temperature, $160^{\circ} \mathrm{C}$ for $5 \mathrm{~min}, 6^{\circ} \mathrm{C} / \mathrm{min}$ to $195^{\circ} \mathrm{C}, 4^{\circ} \mathrm{C} / \mathrm{min}$ to $220^{\circ} \mathrm{C}, 2^{\circ} \mathrm{C} / \mathrm{min}$ to $230^{\circ} \mathrm{C}$, hold $12 \mathrm{~min}$, $1^{\circ} \mathrm{C} / \mathrm{min}$ at $160^{\circ} \mathrm{C}$.

\subsection{Preparation of Samples for Transmission Electron Microscopy}

At the time of killing the animals, the gums were removed and cut appropriately for observation by Transmission Electron Microscopy (TEM). Gum cuts were prefixed in 1.5\% formaldehyde and $1 \%$ cacodylate buffer at $\mathrm{pH} 7.4$ for $2 \mathrm{~h}$ at $4^{\circ} \mathrm{C}$. After three washes in the cacodylate buffer, samples were fixed in $1 \%$ osmium tetroxide for $60 \mathrm{~min}$ at $4^{\circ} \mathrm{C}$. Subsequently, the samples were dehydrated in ethanol and embedded in an Epon resin. After a night long incubation at $65^{\circ} \mathrm{C}$, ultrafine tissue sections were cut with a diamond blade, using an ultracut. These tissue sections were placed on 200 copper mesh screens. All sections were stained with uranyl acetate and contrasted with lead citrate. For its observation, a Carl Zeiss electronic microscope (Oberkochen, Germany) EM10C was used in the Biomedical Research Center of the University of Granada, Health Technology Park.

\subsection{TEM Image Analysis}

Once gingival samples were prepared and observed under TEM, 40,000× magnification images were acquired for Image J [21] analysis. Free-hand tool was selected to round entire mitochondria and the following parameters were measured: area $\left(\mu \mathrm{m}^{2}\right)$; perimeter $(\mu \mathrm{m})$; area:perimeter ratio; length $(\mu \mathrm{m})$; width $(\mu \mathrm{m})$; circularity $[4 \pi \times$ (area) $/(\text { perimeter })^{2}$, which is a bidimensional index of sphericity, where 1 represents the perfect circle and when number tends to 0 means mitochondria is increasingly long; aspect ratio (major axis:minor axis), which represents the relationship between length and width; cytoplasmic area occupied by mitochondria (\%), which represents mitochondrial density in each image; mitochondrial quality, which through a semiquantitative scale join mitochondria in four groups (I-IV) according to integrity.

\subsection{RT-PCR Analysis of Gingival Samples}

After killing the animals, gingival tissue was removed and preserved in RNA later at $-80^{\circ} \mathrm{C}$ until analysis. Total RNA was extracted using RNeasy Lipid Tissue Mini Kit (Qiagen, Hilden, Germany) following manufacturer's condition. The quantity and purity of the RNA were determined from the absorbance at 260/280 nm. About $20 \mathrm{ng}$ of total RNA was reverse-transcribed into cDNA using Multiscribe enzyme (Applied Biosystems, Waltham, Massachusetts, USA) in accordance with the manufacturer's protocol. Abi 7900 Real-Time PCR system and real-time PCR kit (TaqMan ${ }^{\circledR}$ Gene Expression Assays, Applied Biosystems, Waltham, Massachusetts, USA) were used based on the manufacturer's instruction. GUSP was used as an internal control. 
PCR thermal cycling was developed in three steps. Step 1 at $50^{\circ} \mathrm{C}$ lasting $2 \mathrm{~min}$. Step 2 at $95^{\circ} \mathrm{C}$ lasting $10 \mathrm{~min}$, and a final step with 40 cycles at $95^{\circ} \mathrm{C}$ lasting $15 \mathrm{~s}$ and at $60^{\circ} \mathrm{C}$ lasting $1 \mathrm{~min}$.

\subsection{Statistical Analysis}

The results are presented as mean \pm SEM for all representative experiments. Normality (Kolmogorov-Smirnov test) and variance homogeneity (Levene test) were tested. When a variable was found not to follow normal distribution, nonparametric analysis (U Mann-Whitney and Kruskal-Wallis) was followed. For those following normal distribution, one-way ANOVA followed by posthoc analyses (Bonferroni or Tamhane T2) was applied. The level of significance was set at $P<0.05$. SPSS 24.0 (IBM SPSS statistics, Armonk, NY, USA) was used for all statistical analysis.

\section{RESULTS}

\subsection{Gingival Mitochondrial Ultrastructure}

Figure 1 presents area, perimeter, and area:perimeter ratio in gingival mitochondria from rats aged 24 months. For the three studied parameters, animals fed on sunflower oil led to significantly higher values than those fed on virgin olive oil. Animals fed on fish oil did not exhibit differences with the rest of groups.

Figure 2 presents width and height in gingival mitochondria. For both parameters, the lowest values were found in animals fed on virgin olive oil. Those fed on sunflower oil reached the highest values for width and height.

Figure 3 shows circularity of gingival mitochondria. No differences were found between dietary treatments. Figure 4 presents the
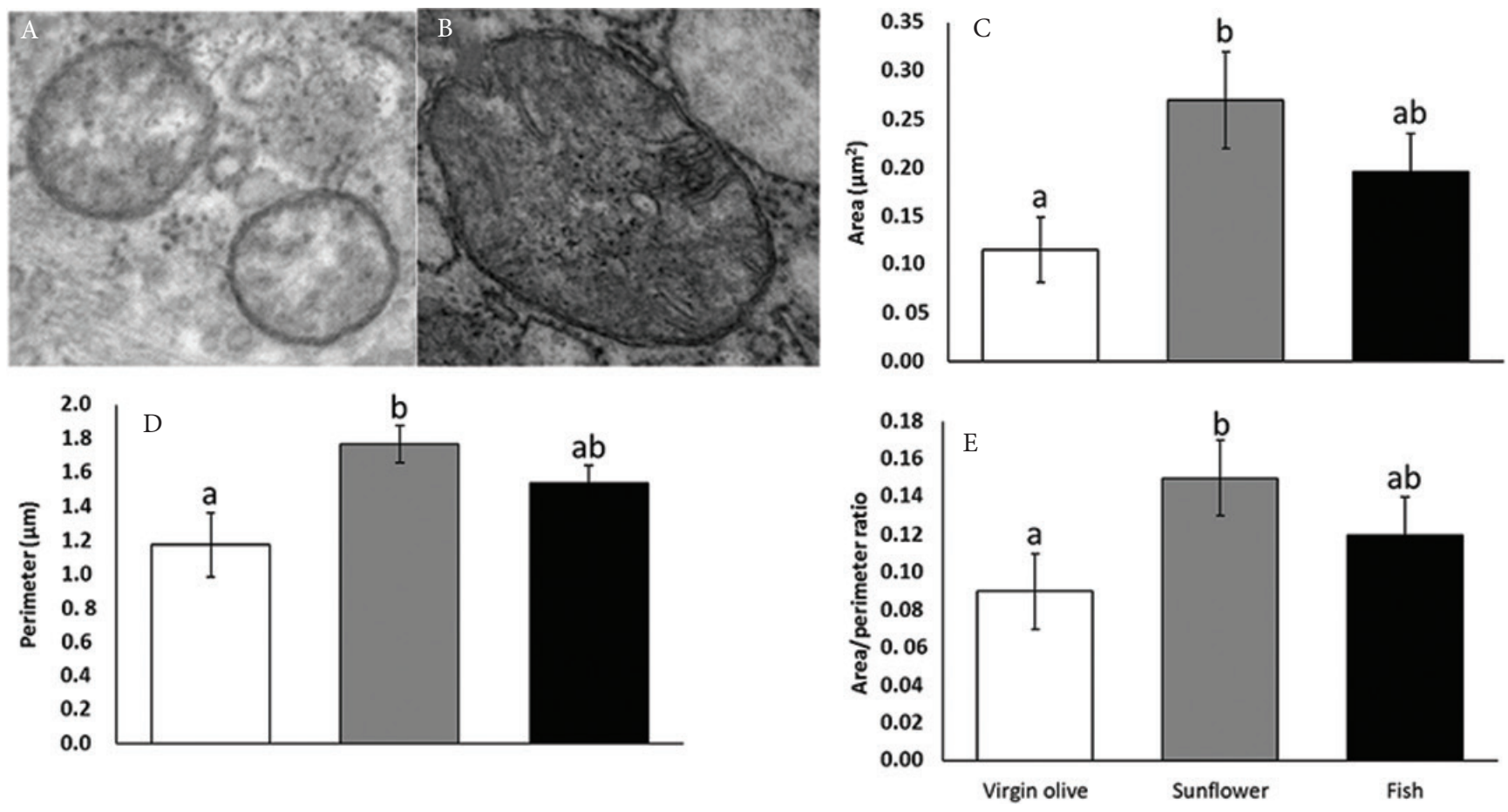

Figure 1 Small (A) and large (B) gingival mitochondria (40,000x) and area (C), perimeter (D), and area:perimeter ratio in gingival mitochondria from old rats fed on virgin olive, sunflower, or fish oil. Columns not sharing superscript letters are significantly different $(p<0.05)$.
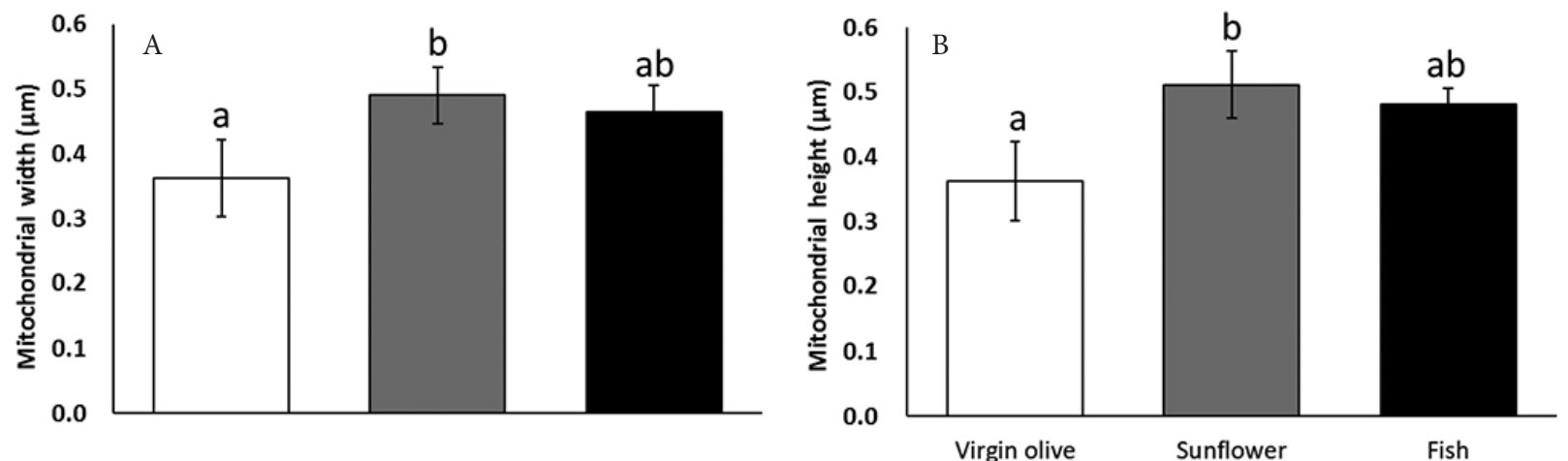

Figure 2 Width (A) and height (B) in gingival mitochondria from old rats fed on virgin olive, sunflower, or fish oil. Columns not sharing superscript letters are significantly different $(p<0.05)$. 


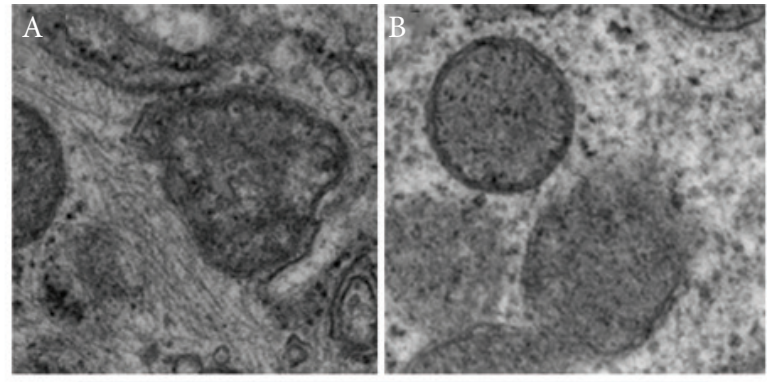

Circularity $=4 \pi(\text { area/perimeter })^{2}$

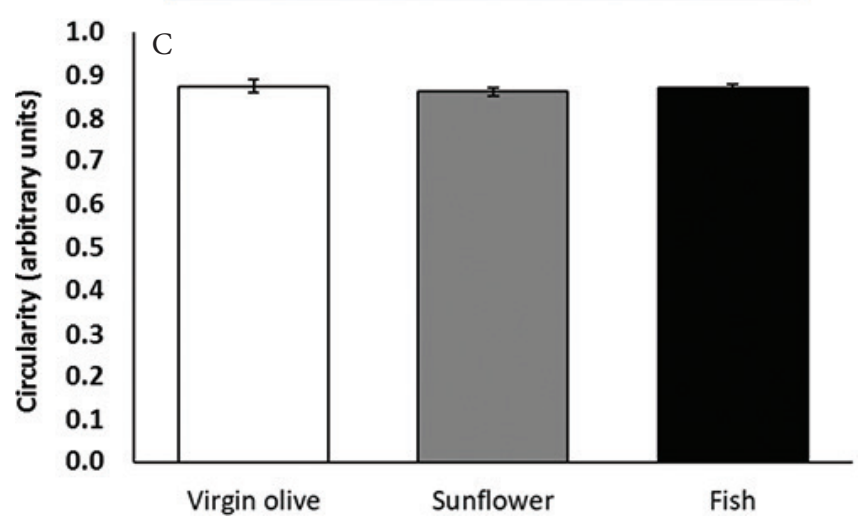

Figure 3 Gingival mitochondria with a low (A) or high level (B) of circularity $(40,000 \times)$, and mean circularity $(C)$ in gingival mitochondria from old rats fed on virgin olive, sunflower, or fish oil.

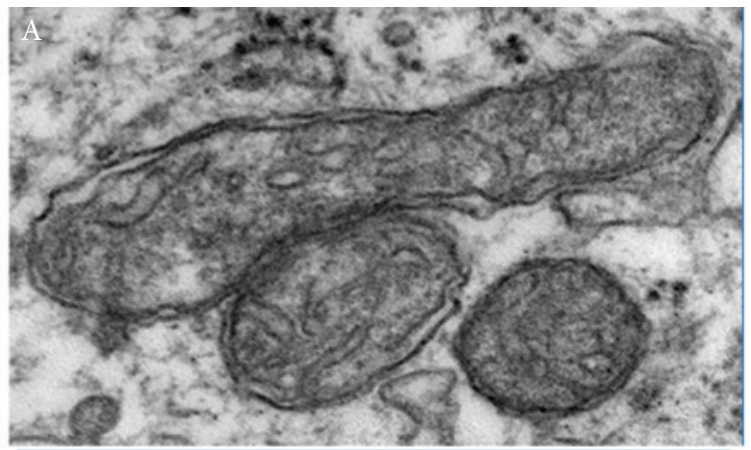

\section{Aspect ratio $=$ (major axis/minor axis)}

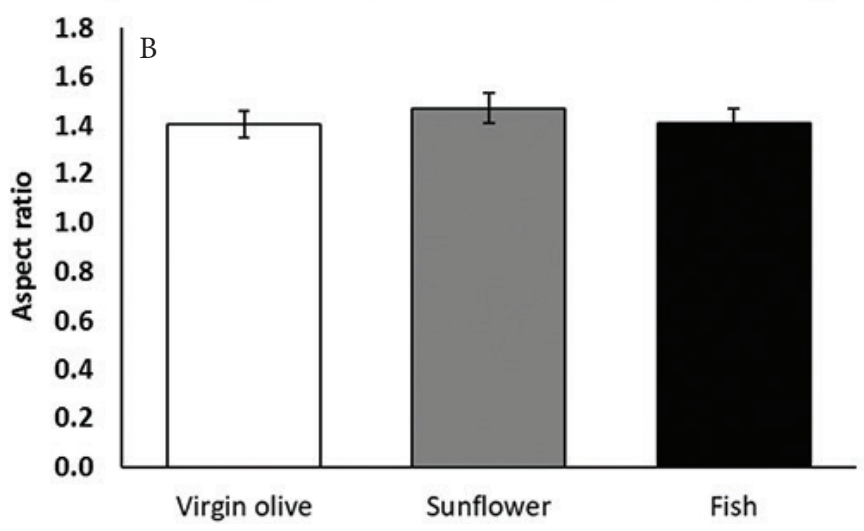

Figure 4 Gingival mitochondria with a (A) high or a low aspect ratio $(40,000 \times)$, and the mean aspect ratio (B) in gingival mitochondria from old rats fed on virgin olive, sunflower, or fish oil.

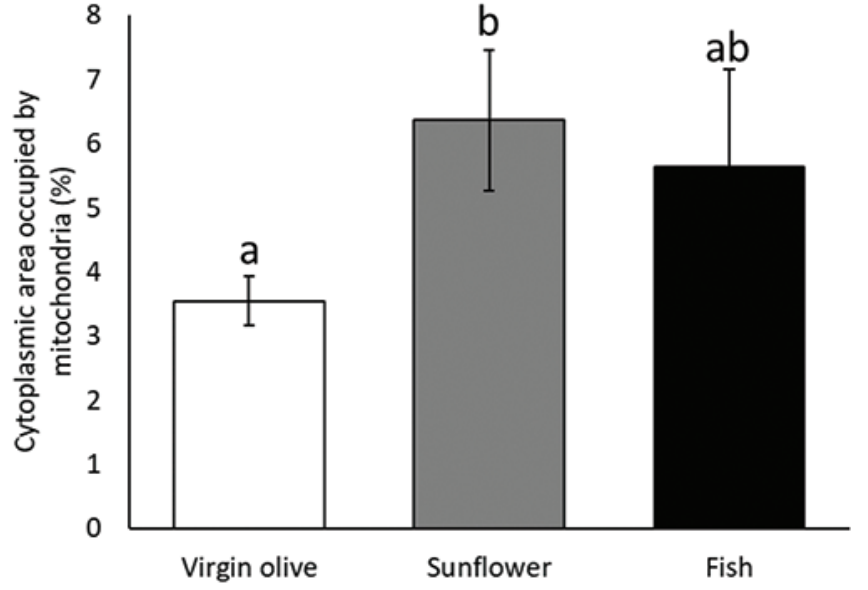

Figure 5 Cytoplasmic area occupied by mitochondria in gingiva from old rats fed on virgin olive, sunflower, or fish oil. Columns not sharing superscript letters are significantly different $(p<0.05)$.

aspect ratio of gingival mitochondria. No statistically significant differences were found between dietary treatments.

Figure 5 shows gingival mitochondrial density presented as the surface of cytoplasm occupied by mitochondria. The lowest density was found in animals fed on virgin olive oil. The highest density was found in sunflower oil fed rats.

Figure 6 shows gingival mitochondrial integrity. No differences were found between the four different categories for all the dietary treatments.

\subsection{Gingival Gene Expression Profiling}

Figure 7 represents gene expression changes (relative mRNA levels) associated with aging in the gingiva of animals fed on virgin olive, sunflower, or fish oils, respectively. Genes associated with mitochondrial mass, apoptosis, electron transport chain, and antioxidant defense were assayed. Concerning mitochondrial mass, no differences were found for MtDNA copy number neither for LC3 gene. Expression of 18S, Tfam, and Atg5 was found to be higher in animals fed on sunflower oil compared with those fed on virgin olive oil, but not with those fed on fish oil. Concerning apoptosis related genes, $\mathrm{Bcl} 2, \mathrm{Bcl} 2 \mathrm{I} 1$, and $\mathrm{Bad}$ expression was higher for animals fed on sunflower oil compared with those fed on virgin olive oil and for Bcl2I1 compared with fish oil group. Neither any differences were found for genes associated with electron transport chain, namely, Ndufs1, MT-ND1, and MT-ND4, nor for the frequency of the ND1/ND4 mtDNA deletion. Finally, concerning antioxidantrelated enzymes, no differences were found for Sod2. Sod 1, Cat, and GPx1 reported to be higher in sunflower oil group compared with virgin olive. Moreover, Gpx1 and Sod1 were found to be higher in the sunflower oil group compared with those in the fish oil group.

\subsection{Plasma Fatty Acids Profile}

Figure 8 shows the plasma lipid profile of old rats. Plasma concentration of $\mathrm{C} 14$ was higher in fish oil-fed rats. No differences 

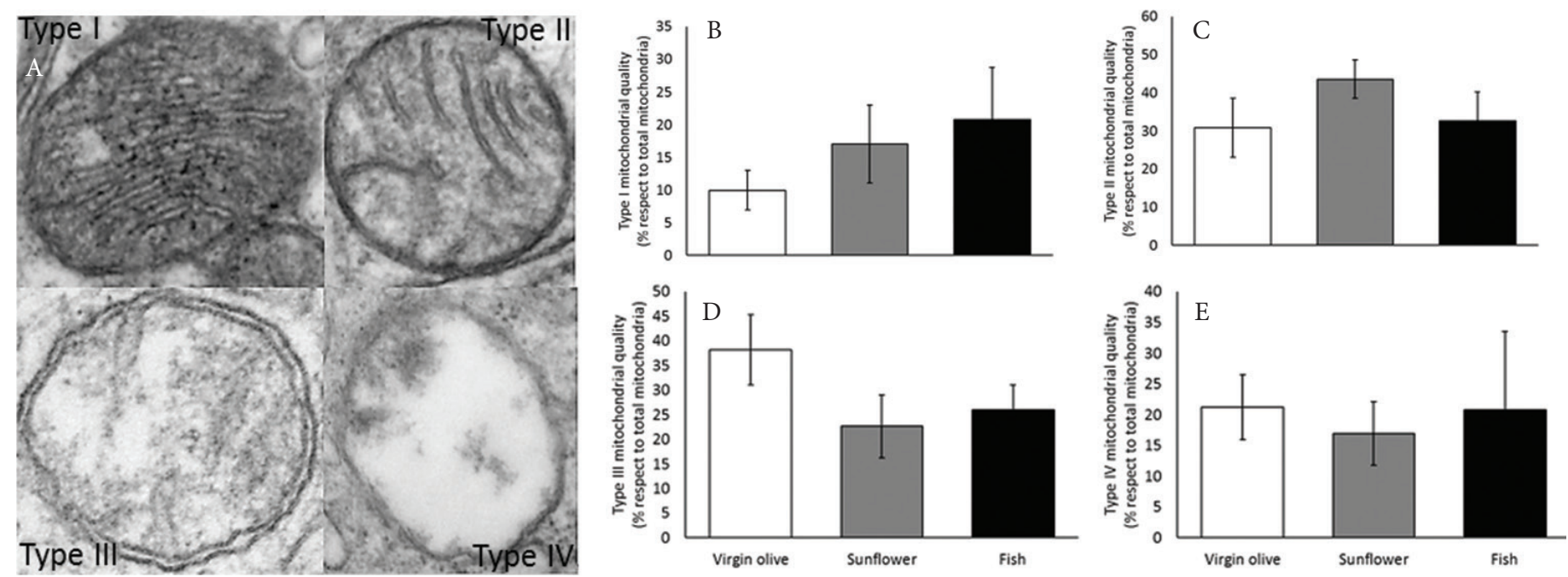

Figure 6 Gingival mitochondria integrity (A) types I, II, III, and IV (40,000×), and mean level for each integrity type (B-E) in gingival mitochondria from old rats fed on virgin olive, sunflower, or fish oil.

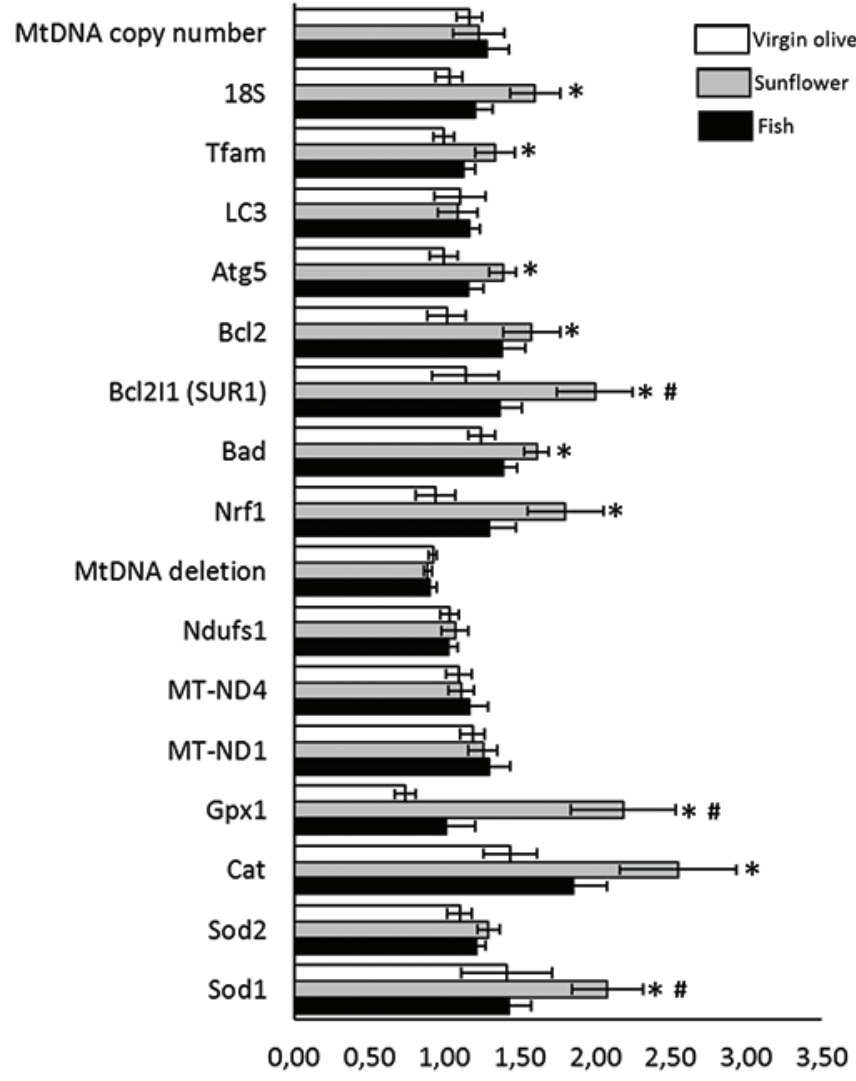

Relative quantity (referred to young control animals)

Figure 7 Gingival mRNA amount (relative quantity compared with 6-month old animals) from old rats fed on virgin olive, sunflower, or fish oil. "Statistical difference $(p<0.05)$ virgin olive oil vs. sunflower oil fed animals. "Statistical difference $(p<0.05)$ fish oil vs. sunflower oil fed animals.

were found for $\mathrm{C} 16$ nor $\mathrm{C} 16: 1 \mathrm{n} 9$ fatty acids. C18 was lower in fish oil group, C18:1n9 was higher in animals fed on virgin olive oil; meanwhile, C18:2n6 was higher in animals fed on sunflower oil, followed by those fed on virgin olive oil, these results were similar for C20:4n6. Concerning C20:5n3, fish oil showed higher values than the rest of the groups. No differences were found for C24:1n9; meanwhile, C22:6n 3 was higher in animals fed on fish oil followed by those fed on virgin olive oil. Regarding indices, total saturated fatty acids were higher in animals fed on sunflower oil compared with those fed on fish oil. Total monounsaturated fatty acids (MUFA) were higher in animals fed on virgin olive oil, total polyunsaturated fatty acids (PUFA) were higher in sunflower oil group. Total n6PUFA were higher in animals fed on sunflower oil; meanwhile, total n3PUFA were higher in fish oil group. MUFA:PUFA ratio was higher in animals fed on virgin olive oil, and finally, n6PUFA:n3PUFA ratio has higher in sunflower oil fed animals followed by those fed on virgin olive oil.

\section{DISCUSSION}

Periodontitis is a pathology related to aging in humans, with older adults showing a much-augmented risk [22,23]. The rat has been showed to be a good model for periodontitis. In that sense, Arai et al. [24] reported that the periodontal bone of rats has similar profiles to humans in terms of resorption with aging. Mitochondria are closely related to the aging process according to the mitochondrial theory of aging [25]. These organelles have also been related to periodontitis in a previous study from our group. In this study, we found that animals fed lifelong on sunflower oil-based diets had higher alveolar bone resorption, a feature of periodontitis [11]. In the present study, using the same approach that in the abovementioned research, we focused on the changes at the mitochondrial ultrastructure.

The initial observations suggesting a connection between mitochondrial structure and function were obtained on ex vivoisolated mitochondria [26]. More recently, a correlation between mitochondrial ultrastructure and output performance has been confirmed $[27,28]$. In the present study, higher mitochondrial area, perimeter, and area:perimeter ratio, a marker of swelling [29], was found in animals fed on sunflower oil compared with those fed on virgin olive oil, although no differences were found 

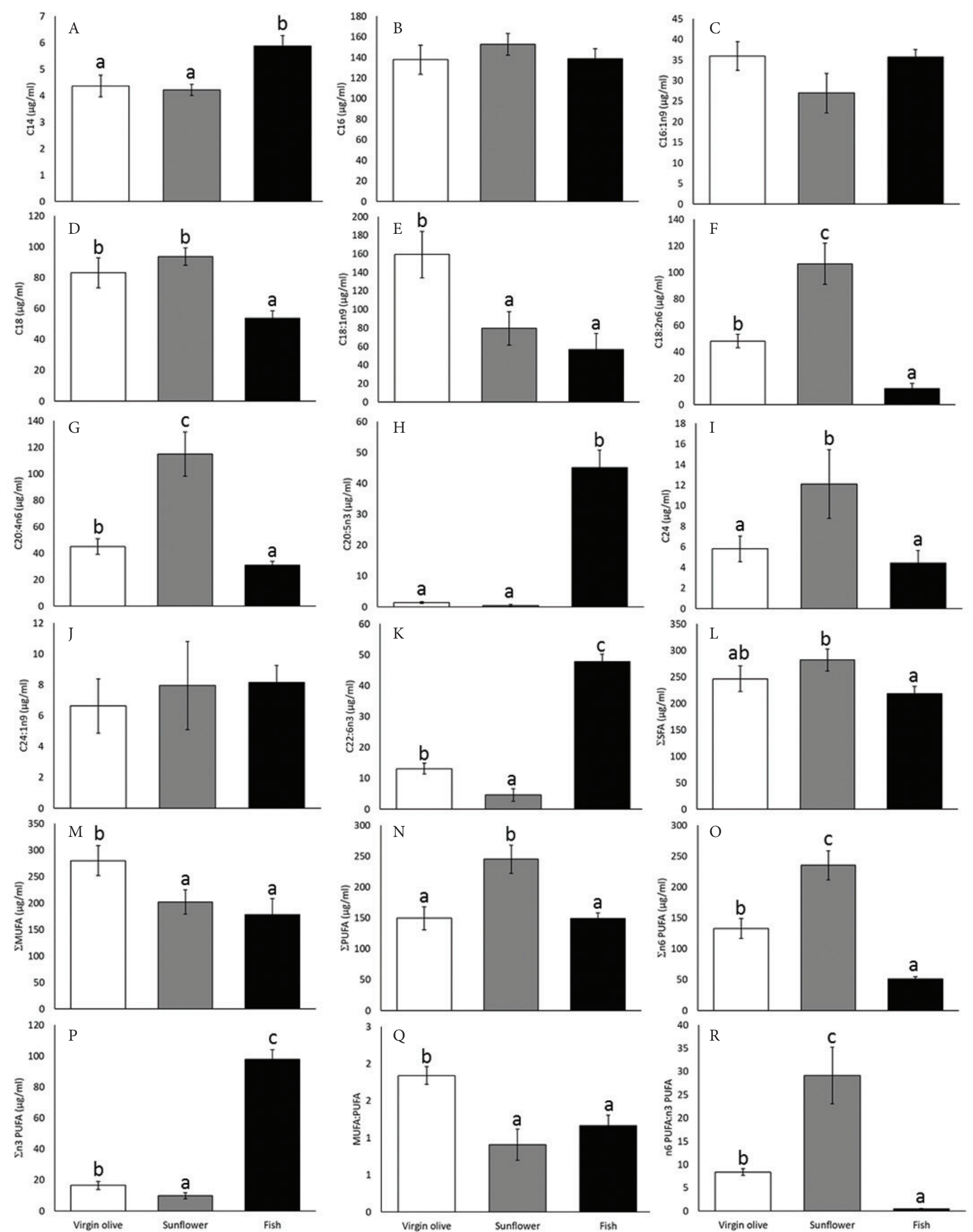

Figure $8 \mid$ Plasma fatty acids profile from old rats fed on virgin olive, sunflower, or fish oil. For each fatty acid or index, columns with different superscript letters are statistically different $(p<0.05)$. MUFA, monounsaturated fatty acids; PUFA, polyunsaturated fatty acids. 
with rats fed on fish oil. These results are similar to those found in the liver of these animals [13]. These features are typical of aged mitochondria [30] and might be related to a process of swelling in animals fed on sunflower oil, as stated for the liver. The width and the height of sunflower oil-fed animals' mitochondria were higher than those from virgin olive oil fed animals. However, no changes were found between dietary treatments neither for circularity, a marker of loss of control [31] nor for aspect ratio, a marker of mitochondrial fission [32]. Contrarily, the cytoplasmic area occupied by mitochondria followed the same behavior observed for area and perimeter, with sunflower oil fed rats reporting the highest values. This parameter could be an approach to the mitochondrial density. Therefore, it seems that feeding with sunflower oil resulted in a greater mitochondrial mass. Fish oil showed intermediate results but without statistically significant differences. The absence of differences in mtDNA copy number suggests that there is a higher cytoplasmic area occupied by mitochondria and the changes observed in morphometry could be attributed to an increase in the size of the mitochondria due to a higher mitochondrial swelling, typical of more aged mitochondria, associated with the sunflower oilbased diet. However, expression of Tfam and $18 \mathrm{~S}$ genes, which are markers of mitochondrial biogenesis [33] suggests that this process would be increased in sunflower oil fed animals according to the mRNA observed levels, although something similar was observed for some genes related to autophagy and apoptosis. However, mRNA levels of genes encoding for mitochondrial electron transport chain components did not show statistically significant differences between treatments. Therefore, as mtDNA copy number can ascertain, biogenesis machinery induction would not be effective to counteract autophagy effects. The expression of some genes supports the idea that the cells try to adapt to the n6PUFA diet, but this is not enough to prevent mitochondrial swelling in aged animals.

As stated, these are not the first observations about the effect of dietary fats on aged mitochondria in different tissues. VarelaLopez et al. [13] reported that sunflower oil led to changes in the morphometry of liver mitochondria, which were associated with changes in the function of these mitochondria. In the same way, Khraiwesh et al. [30] showed that liver mitochondria from calorierestricted mice fed on soy oil also led to changes in the ultrastructure in some aspect similar to those found in gingiva in the present study and in liver in earlier studies [13] for sunflower oil-fed animals. Noteworthy, soy and sunflower oils are very rich in n6PUFA, so the lipid profile might be responsible, at least in part, for the observed findings. When circulating lipid profile is studied, it can be observed that dietary lipid profile was reflected in plasma, with animals fed on virgin olive oil showing a higher concentration of oleic acid and the rest of MUFA than the other dietary treatments. Similarly, animals fed on sunflower oil led to higher amounts of linoleic acid and the other n6PUFA; meanwhile, n3PUFA were found to be higher in fish oil-fed animals. Similar to that happening, in the present study the plasma, liver, heart, and muscle mitochondria have shown similar adaptations to lipid profile in the past [34-36]. In the present study, and because the small amount of available tissue it was not possible to evaluate fatty acid profile in gingival tissue.

Changes observed in mitochondrial ultrastructure might be related with other mitochondrial features derived from the particular fatty acid composition of membranes after dietary intake of different unsaturated fats for the whole life. In this sense, it has been observed earlier that lipid peroxidation was higher in gingival tissue of aged rats fed on sunflower oil [11]. This effect on oxidative stress can be indirectly followed in the present study through the analysis of gene expression. Thus, the mRNA levels of some antioxidant enzymes, namely Gpx1, Cat and SOD1, were higher in the animals fed on sunflower oil. Concerning another mitochondrial markers of damage, such as ND1/ND4 deletion, no differences were found, which is in opposition to observations from the liver of old rats fed on sunflower oil at an $8 \% \mathrm{w} / \mathrm{w}$ [31].

Summarizing, lifelong feeding on different dietary unsaturated fats affects mitochondrial ultrastructure and gene expression in the gingiva of old rats in different ways. Those fed on sunflower oil, a dietary fat type rich in n6PUFA, showed important differences in such aspects compared with animals fed on virgin olive oil, mainly rich in MUFA. However, differences found in animals fed on fish oil with respect to any of the other two dietary fats were not enough to reach statistically significant differences. As old rats fed lifelong on sunflower oil have showed higher alveolar bone resorption in earlier studies, a major feature of periodontitis, we could conclude that age-related alveolar bone resorption associated with n6PUFA would be, at least in part, mediated by changes in the ultrastructure of mitochondria at the gingival tissue. This should be considered in the future when therapies against periodontitis or dietary treatments to prevent this disease would be formulated.

\section{CONFLICTS OF INTEREST}

The authors declare they have no conflicts of interest.

\section{AUTHOR CONTRIBUTIONS}

M.D.N.-H. wrote the manuscrit and performed some experiments; A.V.-L. performed some experiments and contributed to discussion of the results; J.M.R.-M. performed some experiments; C.P.-M. performed some experiments; P.B. helped in experiment design, funding and discussion; T.Y.F.-H. performed some experiments and helped with discussion of the manuscript; J.L.Q. designed the experimets, supervised experiments, discussion and manuscript preparation and obtained funding for the study.

\section{ACKNOWLEDGMENTS}

This work was supported by I + D grants from the Spanish Ministry of Education and Science [AGL2008-01057] and the Government of Andalusia [AGR832]. María D. Navarro-Hortal and José M. Romero-Márquez are FPU fellows from the Spanish Ministry of Educación y Formación Profesional.

\section{REFERENCES}

[1] Hegde R, Awan KH. Effects of periodontal disease on systemic health. Dis Mon 2019;65:185-92. 
[2] Hodes RJ, Sierra F, Austad SN, Epel E, Neigh GN, Erlandson KM, et al. Disease drivers of aging. Ann N Y Acad Sci 2016;1386: $45-68$.

[3] Bosshardt DD. The periodontal pocket: pathogenesis, histopathology and consequences. Periodontol 2000 2018;76:43-50.

[4] Kiefte-de Jong JC, Mathers JC, Franco OH. Nutrition and healthy ageing: the key ingredients. Proc Nutr Soc 2014;73:249-59.

[5] Najeeb S, Zafar MS, Khurshid Z, Zohaib S, Almas K. The role of nutrition in periodontal health: an update. Nutrients 2016;8: pii: E530.

[6] Pearlman M, Akpotaire O. Diet and the role of food in common gastrointestinal diseases. Med Clin North Am 2019;103:101-10.

[7] Siri-Tarino PW, Krauss RM. Diet, lipids, and cardiovascular disease. Curr Opin Lipidol 2016;27:323-8.

[8] Lawrence GD. Dietary fats and health: dietary recommendations in the context of scientific evidence. Adv Nutr 2013;4: 294-302.

[9] Sacks FM, Lichtenstein AH, Wu JHY, Appel LJ, Creager MA, Kris-Etherton PM, et al. Dietary fats and cardiovascular disease: a presidential advisory from the American Heart Association. Circulation 2017;136:e1-e23.

[10] Nanji AA. Role of different dietary fatty acids in the pathogenesis of experimental alcoholic liver disease. Alcohol 2004;34:21-5.

[11] Bullon P, Battino M, Varela-Lopez A, Perez-Lopez P, GranadosPrincipal S, Ramirez-Tortosa MC, et al. Diets based on virgin olive oil or fish oil but not on sunflower oil prevent age-related alveolar bone resorption by mitochondrial-related mechanisms. PLoS One 2013;8:e74234.

[12] Lada AT, Rudel LL. Dietary monounsaturated versus polyunsaturated fatty acids: which is really better for protection from coronary heart disease? Curr Opin Lipidol 2003;14:41-6.

[13] Varela-Lopez A, Pérez-López MP, Ramirez-Tortosa CL, Battino M, Granados-Principal S, Ramirez-Tortosa MDC, et al. Gene pathways associated with mitochondrial function, oxidative stress and telomere length are differentially expressed in the liver of rats fed lifelong on virgin olive, sunflower or fish oils. J Nutr Biochem 2018;52:36-44.

[14] Marion-Letellier R, Savoye G, Ghosh S. Polyunsaturated fatty acids and inflammation. IUBMB Life 2015;67:659-67.

[15] Mataix J, Ochoa JJ, Quiles JL. Olive oil and mitochondrial oxidative stress. Int J Vitam Nutr Res 2006;76:178-83.

[16] Quiles JL, Huertas JR, Mañas M, Battino M, Mataix J. Physical exercise affects the lipid profile of mitochondrial membranes in rats fed with virgin olive oil or sunflower oil. Br J Nutr 1999;81:21-4.

[17] Perona JS. Membrane lipid alterations in the metabolic syndrome and the role of dietary oils. Biochim Biophys Acta Biomembr 2017;1859:1690-703.

[18] Schiff M, Bénit P, Coulibaly A, Loublier S, El-Khoury R, Rustin P. Mitochondrial response to controlled nutrition in health and disease. Nutr Rev 2011;69:65-75.

[19] Reeves PG, Nielsen FH, Fahey GC Jr. AIN-93 purified diets for laboratory rodents: final report of the American Institute of Nutrition ad hoc writing committee on the reformulation of the AIN-76A rodent diet. J Nutr 1993;123:1939-51.

[20] Lepage G, Roy CC. Specific methylation of plasma nonesterified fatty acids in a one-step reaction. J Lipid Res 1988;29: 227-35.
[21] Rueden CT, Schindelin J, Hiner MC, DeZonia BE, Walter AE, Arena ET, et al. Image 2: ImageJ for the next generation of scientific image data. BMC Bioinformatics 2017;18:529.

[22] Dietrich T, Jimenez M, Krall Kaye EA, Vokonas PS, Garcia RI. Age-dependent associations between chronic periodontitis/ edentulism and risk of coronary heart disease. Circulation 2008; 117:1668-74.

[23] Nesbitt MJ, Reynolds MA, Shiau H, Choe K, Simonsick EM, Ferrucci L. Association of periodontitis and metabolic syndrome in the Baltimore Longitudinal Study of Aging. Aging Clin Exp Res 2010;22:238-42.

[24] Arai K, Tanaka S, Yamamoto-Sawamura T, Sone K, Miyaishi O, Sumi Y. Aging changes in the periodontal bone of F344/N rat. Arch Gerontol Geriatr 2005;40:225-9.

[25] Miquel J, Economos AC, Fleming J, Johnson JE Jr. Mitochondrial role in cell aging. Exp Gerontol 1980;15:575-91.

[26] Hackenbrock CR. Ultrastructural bases for metabolically linked mechanical activity in mitochondria. I. Reversible ultrastructural changes with change in metabolic steady state in isolated liver mitochondria. J Cell Biol 1966;30:269-97.

[27] Cogliati S, Enriquez JA, Scorrano L. Mitochondrial cristae: where beauty meets functionality. Trends Biochem Sci 2016;41:261-73.

[28] Cserép C, Pósfai B, Schwarcz AD, Dénes Á. Mitochondrial ultrastructure is coupled to synaptic performance at axonal release sites. eNeuro 2018;5: pii: ENEURO.0390-17.2018.

[29] Angelin A, Tiepolo T, Sabatelli P, Grumati P, Bergamin N, Golfieri C, et al. Mitochondrial dysfunction in the pathogenesis of Ullrich congenital muscular dystrophy and prospective therapy with cyclosporins. Proc Natl Acad Sci U S A 2007;104:991-6.

[30] Khraiwesh H, López-Domínguez JA, Fernández del Río L, Gutierrez-Casado E, López-Lluch G, Navas P, et al. Mitochondrial ultrastructure and markers of dynamics in hepatocytes from aged, calorie restricted mice fed with different dietary fats. Exp Gerontol 2014;56:77-88.

[31] Quiles JL, Ochoa JJ, Ramirez-Tortosa MC, Huertas JR, Mataix J. Age-related mitochondrial DNA deletion in rat liver depends on dietary fat unsaturation. J Gerontol A Biol Sci Med Sci 2006;61:107-14.

[32] Liu MY, Jin J, Li SL, Yan J, Zhen CL, Gao JL, et al. Mitochondrial fission of smooth muscle cells is involved in artery constriction. Hypertension 2016;68:1245-54.

[33] Ventura-Clapier R, Garnier A, Veksler V. Transcriptional control of mitochondrial biogenesis: the central role of PGC-1alpha. Cardiovasc Res 2008;79:208-17.

[34] Ochoa JJ, Quiles JL, Ibáñez S, Martínez E, López-Frías M, Huertas JR, et al. Aging-related oxidative stress depends on dietary lipid source in rat postmitotic tissues. J Bioenerg Biomembr 2003;35:267-75.

[35] Quiles JL, Martínez E, Ibáñez S, Ochoa JJ, Martín Y, López-Frías M, et al. Ageing-related tissue-specific alterations in mitochondrial composition and function are modulated by dietary fat type in the rat. J Bioenerg Biomembr 2002;34:517-24.

[36] Roche E, Ramírez-Tortosa CL, Arribas MI, Ochoa JJ, SirventBelando JE, Battino M. Comparative analysis of pancreatic changes in aged rats fed life long with sunflower, fish, or olive oils. J Gerontol A Biol Sci Med Sci 2014;69:934-44. 